\title{
A Consciência Ambiental e as Atitudes de Consumo Sustentável de Estrangeiros ${ }^{1}$
}

\author{
The Environmental Awareness and Sustainable Consumption \\ Attitudes Foreigners
}

\section{La conciencia ambiental y actitudes de consumo sostenibles Extranjeros}

\author{
Larissa Back \\ Universidade Federal do Rio Grande do Sul (UFGRS), Administradora. \\ Endereço: Rua da Matriz, n.446, Centro - Itapiranga/ SC, Brasil, CEP: 89896-000 \\ Telefone: (49) 3677-3193, e-mail: larissaback@yahoo.com.br \\ Ivanete Schneider Hahn, Me. \\ Universidade Federal de Santa Maria (UFSM) e Universidade Alto Vale do Rio do Peixe (UNIARP) \\ Endereço: Rua Fernando Machado, n.403, apto 302, centro - Caçador/SC, Brasil CEP: 89500-000, Telefone: (49) \\ 9954-8420, e-mail: ivischneider@hotmail.com \\ Flavia Luciane Scherer, Dr ${ }^{\mathrm{a}}$ \\ Universidade Federal de Santa Maria (UFSM) \\ Programa de pós-graduação em Administração (PPGA) \\ Endereço: Dr. Bozano, n.541, apto 702, Centro - Santa Maria/RS, Brasil, CEP: 97015-001 \\ Telefone: (55) 3220-9296, e-mail: flaviasherer@globo.com.br
}

\begin{abstract}
RESUMO
O objetivo deste trabalho foi identificar a consciência ambiental e as atitudes de consumo sustentável de estrangeiros. Como método de investigação utilizou-se um levantamento do tipo survey, com estrangeiros, ou seja, não brasileiros (nem natos e nem naturalizados). Obteve-se 78 questionários válidos, com respondentes de 26 nacionalidades. A análise dos dados aconteceu por meio de análise estatística descritiva e univariada. Os resultados evidenciam, em grosso modo, que tanto a consciência ambiental quanto as atitudes de consumo sustentável da amostra possuem tendência intermediária, sendo que grande parte dos respondentes parece não utilizar-se do viés ambiental na escolha dos produtos que irá consumir. Infere-se ainda, que os respondentes mostram respeitar o meio ambiente, desde que os meios utilizados na implementação desse 'seu respeito' não afetem seu próprio conforto e bem-estar.
\end{abstract}

Palavras-chave: Sustentabilidade. Consciência ambiental. Consumo sustentável.

ABSTRACT

\footnotetext{
1 Artigo recebido em 05.08.2014. Revisado pelos pares em 07.03.2015 (blind review). Ajustado e Aceito para publicação em 09.07.2015. Recomendado para publicação por José Ribamar Marques de Carvalho (Editor Científico). Publicado em 06.08.2015. Organização responsável UACC/CCJS/UFCG.
} 
This study objective to identify the environmental awareness and the sustainable consumption attitudes of foreigners, ie nonBrazilian (not native nor naturalized). The method of investigation used was a survey. We obtained 78 valid questionnaires, with respondents from 26 nationalities. The data analysis took place using descriptive and univariate statistical analysis. The results show, in roughly, that environmental consciousness and sustainable consumption attitudes of the sample have intermediate trend, and the most respondents seems to use up the environmental bias in choosing the products that will consume. It is inferred also that respondents respect the environment, if the means used to implement this do not affect their own comfort and well-being.

Keywords: Sustainable; Environmental awareness; Sustainable consumption.

RESUMEN

El objetivo de este estudio fue identificar la conciencia ambiental y las actitudes de de consumo sostenible de los extranjeros. El método de investigación utilizó una survey, con los extranjeros, es decir, no brasileño (ni nacido ni naturalizado). Se obtuvieron 78 cuestionarios válidos, con entrevistados de 26 nacionalidades. El análisis de datos se llevó a cabo utilizando un análisis estadístico descriptivo y univariante. Los resultados muestran que tanto la conciencia del medio ambiente y las actitudes de consumo sostenibles de la muestra tienen tendencia intermedia, y que la mayoría de los entrevistados parece utilizar el sesgo ambiental en la elección de los productos que van a consumir. También, los entrevistados muestran respeto al medio ambiente, si los medios utilizados para implementar esto no afectará a su propia comodidad y bienestar.

Palabras clave: Sostenibilidad. La conciencia ambiental. El consumo sostenible.

\section{INTRODUÇÃO}

As estratégias de marketing empresariais devem atender as especificidades dos consumidores do mercado-alvo, e existe uma crescente demanda de produtos sustentáveis (LAROCHE; BERGERON; FORLEO, 2001; TÓDERO; MACKE, 2008; SOUZA, 2012), e as empresas vem acompanhando o surgimento deste consumidor preocupado com o ambiente. Já na década de 1970, Kinnear e Taylor (1972) alertavam que as decisões pessoais de consumo podem contribuir na preservação ou na deterioração do meio ambiente, ao mesmo tempo em que Hartmann e Ibáñes (2006) explicam que o comportamento de compra sustentável é vital para a transformação social.

$\mathrm{Na}$ literatura, encontram-se diversos estudos (por exemplo: KINNEAR; TAYLOR, 1972; BEDANTE, 2004; PORTILHO, 2005; BERGER; CUNNINGHAM; DRUMWRIGHT, 2006; COSTA; TEODÓSIO, 2011; SANTOS; SILVA, 2011; GORNI; GOMES; DREHER, 2011; SOUZA, 2012; ARANCIBIA, 2012) que focaram em identificar o perfil do consumidor ambientalmente consciente, bem como variáveis psicográficas e comportamentais deste consumidor. Como forma de verificar uma lacuna teórica, esse estudo objetiva identificar a consciência ambiental e as atitudes de consumo sustentável no âmbito internacional.

O estudo justifica-se a partir do momento em que as empresas brasileiras vêm investindo em mercados alternativos, normalmente no âmbito internacional. Nesse sentido, a literatura apresenta uma grande discussão em relação à escolha da melhor estratégia de marketing a ser adotada no exterior, uma vez que parte dos autores 
defendem a adoção de uma estratégia global e padronizada de marketing (que se justificaria no advento da globalização) e outra parte dos autores defende a adaptação das estratégias de marketing a cada país alvo - composto de marketing e as estratégias de marca devem ser tratados de forma diferenciada para cada mercado, embasados pelas diferenças econômicas, socioculturais, geográficas. (SOLBERG, 2002; SAAD; MELLO; CHAUVEL, 2006; COSTA; LANDEIRA; SILVA, 2007; CUNHA; ROCHA, 2011)

O trabalho foi estruturado em seis partes. Inicialmente, objetivou a contextualização dos aspectos gerais do trabalho, justificando as motivações e a importância do tema para o mundo acadêmico e empresarial. A segunda e terceira parte do estudo resgatam os conceitos teóricos e perspectivas sobre a sustentabilidade e o consumo sustentável e a consciência ambiental. Na quarta parte, apresenta-se a perspectiva metodológica do trabalho, os procedimentos e instrumentos utilizados para a coleta e tratamento dos dados. Na quinta parte, expõe-se a apresentação e análise dos resultados. E por fim, apresentam-se as considerações finais e recomendações.

\section{A SUSTENTABILIDADE}

Nos três últimos séculos surgiram novas técnicas produtivas devido às revoluções industriais e tecnológicas, o que aumentou rapidamente a capacidade de produção. Porém, tamanha velocidade do crescimento e a consequente necessidade de geração de riquezas acabaram resultando em vários efeitos colaterais para a sociedade, na qual a o modelo produtivo se insere e culminou a discussão sobre a impossibilidade de subsistência. (OLIVEIRA et al., 2012)

Nas décadas de 50, 60 a visão equivocada de que os recursos naturais eram intermináveis e estavam à disposição do homem exigiu maior reflexão da humanidade. $\mathrm{O}$ que se questionava era que, embora tivessem ocorrido profundas mudanças na economia, os níveis de subdesenvolvimento e pobreza não abaixavam, e em muitos casos aumentavam; além disso, a desigualdade social entre os países desenvolvidos e subdesenvolvidos se tornava cada vez maior (DIAS, 2009). Esses questionamentos instigaram diversas correntes de pensamento, por meio de estudos e pesquisas ao longo do tempo, contribuindo para a inserção da sustentabilidade (principalmente a dimensão ambiental) na análise econômica das organizações.

Em 1962, a bióloga Rachel Carson denunciou a crise ambiental em meados da década de 70, os processos de degradação ambiental e a possibilidade de esgotamento de determinados recursos naturais se tornaram mais evidentes. Com isso os questionamentos tornaram-se mais sólidos sobre o modelo econômico que persistia desde a Revolução em torno do uso de pesticidas e inseticidas químicos (NASCIMENTO, 2012) por meio da publicação do livro Silent Spring (1962), 
defendendo o uso de controles biológicos, que consistem na utilização de fungos, bactérias e insetos para combater os parasitas que se nutrem das plantas. Isso trouxe grande repercussão na opinião pública e resultou na preocupação por parte de muitos países em relação aos danos causados ao meio ambiente, realizando intensa inspeção de terras, rios, mares e ares segundo (DIAS, 2009).

No ano de 1968, em Roma - Itália reuniram-se intelectuais e estudiosos de dez países, em um encontro chamado de Clube Roma, cujo objetivo era discutir e promover o entendimento de assuntos relacionados à política, economia, natural e social, em seguida divulgar ao mundo todo, principalmente aos líderes, este novo entendimento buscando novas iniciativas e planos de ação dos dilemas atuais e futuros da humanidade (DIAS, 2009). Por solicitação do Clube de Roma foi realizado um trabalho de investigação dos assuntos tratados no encontro por uma equipe do Massachusetts Institute of Technology (MIT) coordenada por Donella Meadows, e os resultados foram publicados no texto intitulado Limits to Growth em 1972.

Esse estudo concluía que se continuada a tendência de crescimento dos níveis de industrialização, poluição, produção de alimentos e exploração dos recursos naturais, os limites de crescimento do planeta seriam atingidos, no máximo, em cem anos, provocando uma repentina diminuição da população mundial e da capacidade industrial (MEADOWS et al., 1972). O estudo ganhou destaque sendo debatido na United Nations Conference on the Human Environment (UNCHE) no mesmo ano, em Estocolmo. O evento em Estocolmo foi o primeiro encontro realizado em nível mundial que manifestou a preocupação com as questões ambientais, no intuito de debater sobre o assunto e buscar soluções para a preservação da humanidade. A palavra sustentabilidade tornou-se mundialmente conhecida (DIAS, 2009).

Mais tarde, em 1982 acontece a Conferência de Nairobi, promovida pela Unep - ONU, onde foi criada a Comissão Mundial sobre o Meio Ambiente e Desenvolvimento, então chefiada pela primeira-ministra da Noruega, Gro Harlem Brundtland. E, em 1987, os resultados do trabalho tornaram-se públicos, por meio do documento chamado de Our Common Future também conhecido como Relatório Brundtland. (ROMEIRO, 2012)

O documento traz o conceito de "desenvolvimento sustentável" para o discurso público (OUR COMMON FUTURE, 1987), conceituando-o como o" desenvolvimento que satisfaz as necessidades do presente sem comprometer a capacidade das gerações futuras de satisfazerem as suas próprias necessidades". Conforme Haswani $(2008$, p. 2) o conceito foi motivado pela "constatação de que o modelo de crescimento econômico, até então adotado, gerou riqueza e fartura nunca antes vistas pelo homem, mas às custas da miséria, da degradação ambiental e da poluição crescentes".

O estudo e o debate sobre conceito de desenvolvimento sustentável auferiu ampla dimensão o que levou à realização da Conferência das Nações Unidas sobre o 
Meio Ambiente e o Desenvolvimento da chamada Cúpula da Terra ocorrida em 1992, no Rio de Janeiro - Brasil, cujas conclusões serviram de base para a formulação de documentos oficiais: três convenções (biodiversidade, desertificação e mudanças climáticas) que resultou mais tarde no Protocolo de Kyoto (uma declaração de princípios sobre florestas) (NASCIMENTO, 2012; HASWANI, 2008).

Outros eventos importantes ocorreram após 1992, a exemplo do (1) Protocolo de Kyoto (1997) documento assinado por diversos países comprometendo-se a reduzir suas emissões de gases de efeito estufa; a (2) Cúpula Mundial sobre Desenvolvimento Sustentável, em Johanesburgo - África do Sul (2002) no intuito de fazer um balanço das conquistas, desafios e das novas questões surgidas desde a Cúpula da Terra de 1992; (3) COP15, Convenção do Clima de Copenhague, na Dinamarca em 2009, sendo que o encontro teve como finalidade negociar, redigir e aprovar os termos da segunda parte do Protocolo de Kyoto (1997) com novos prazos para cumprir as metas de redução de emissão de gases; (4) Conferência das Nações Unidas sobre Desenvolvimento Sustentável - Rio +20, no Rio de Janeiro (2012), serviu para renovar e reafirmar a participação dos líderes dos 193 países com relação ao desenvolvimento sustentável no planeta Terra, onde originou um documento final apresentando intensões e medidas práticas para proteger o meio ambiente planejando os próximos anos.

Ante o exposto, enfatiza-se a responsabilidade dos governos em relação do desenvolvimento sustentável. Contudo, deve-se responsabilizar solidariamente as empresas para consolidar as práticas sustentáveis, haja vista que o desenvolvimento sustentável deve ser um esforço conjunto da sociedade, empresas e governo. Tais afirmações corroboram com Souza (2012) que afirma que por muitos anos as preocupações ambientais e sociais competiam somente ao Estado. Todavia, o autor ressalta que na atualidade diferentes agentes da sociedade mostram-se preocupados com estas questões.

John Elkington, fundador da SustainAbility, fez importante contribuição para consolidar o entendimento de desenvolvimento sustentável nas empresas. Em 1997, o autor propôs em seu livro Cannibals with Forks the Triple Bottom Line of 21st Century Busines, o termo Triple Bottom Line, conferindo as empresas a responsabilidade em suas operações de estabelecer um equilíbrio tanto nos retornos econômicos, sociais e ambientais. (ELKINGTON, 1998)

Conforme Dias (2009), para que haja sustentabilidade é necessário que as três dimensões - econômica, social e ambiental - sejam atendidos simultaneamente, como está representado pela figura 1 .

\section{Figura 1 - Equilíbrio dinâmico da sustentabilidade}




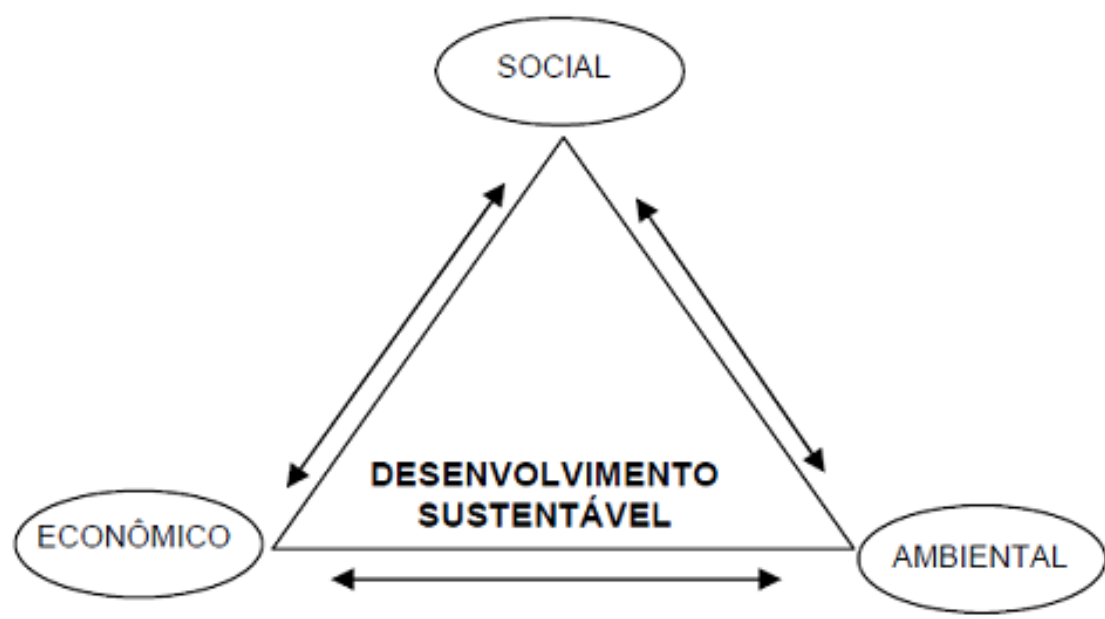

Fonte: DIAS (2009, p. 41)

De acordo com Dias (2009), no âmbito econômico, a sustentabilidade considera que as empresas têm que ser economicamente viáveis, isto é, seu dever com a sociedade é ser rentável. No ponto de vista social, a empresa deve proporcionar condições dignas aos seus empregados, ser adepta a diversidade cultural, proporcionar oportunidade aos deficientes em geral e os dirigentes participantes ativos de ações socioculturais com a comunidade que cerca a unidade produtiva. Por fim, em termo ambiental, a organização deve fundamentar-se em ações de ecoeficiência dos seus processos produtivos, adotar produção mais limpa, proporcionar condições para o desenvolvimento de uma cultura ambiental organizacional, entre outras.

A partir desta nova visão de sustentabilidade, surgiram questões sobre a operacionalização e implementação das práticas sustentáveis. Neste contexto, evidencia-se o incentivo ao desenvolvimento de uma consciência ambiental para incentivar o consumo sustentável, temas apresentados na próxima seção.

\section{A CONSCIÊNCIA AMBIENTAL E AS ATITUDES DE CONSUMO SUSTENTÁVEL}

O aumento do consumo de bens produzidos pelo sistema industrial é motivo de sucesso da economia do sistema capitalista. Porém, esta abundância passou a ser alvo de críticas, relacionando o consumismo como um dos principais problemas da sociedade moderna, marcada por intensas inovações que afetam nossas experiências de consumo, como a biotecnologia e comércio eletrônico, bem como por uma nova postura consumidora, aquela consciente e preocupada com a sustentabilidade.

A Agenda 21 Global, assinada na Rio 92, traz em seu Capítulo 4 a relevância em se atentar para o consumo como causador de diferentes impactos ambientais e sociais. De acordo com o Ministério do Meio Ambiente (MMA) (2013), o consumo 
sustentável, envolve a utilização de menos recursos naturais em sua produção, promova a valorização dos recursos humanos e que possam ser facilmente reaproveitados ou reciclados. Para o autor, significa comprar aquilo que realmente é necessário, respeitando ao máximo o tempo de vida útil dos produtos.

Todavia, a mudança do comportamento de consumo ocorre apenas quando a sociedade adota novos valores, o que normalmente leva tempo. Para o MMA (2013, p.1), “o termo 'sociedade de consumo' foi cunhado para denominar a sociedade global baseada no valor do 'ter'". Contudo, de acordo com o autor supracitado, o que se observa são os valores de sustentabilidade e justiça social fazendo parte da consciência coletiva, no mundo e aos poucos, também no Brasil. Esta nova abordagem, mais consciente ambientalmente, é capaz de promover mudanças em relação ao consumo, abandonando práticas nocivas de alto consumo e desperdício.

Diante da disseminação e popularização do estilo de vida e de consumo dos países desenvolvidos do ocidente (BEDANTE, 2004) vêm havendo maior ênfase no desenvolvimento de uma consciência sustentável. Inevitavelmente uma consciência sustentável culmina em novos hábitos de consumo. A emergência desse consumidor mais agressivo e exigente reflete em grande parte as mudanças que a própria sociedade vem sofrendo quanto a valores e ideologias e que envolvem suas expectativas em relação às empresas e aos negócios. Esses novos valores e ideologias incluem a democracia, a igualdade de oportunidades, a saúde e a segurança no trabalho, a proteção ao consumidor, um meio ambiente mais limpo, entre outras questões (SANCHES, 2000). O que se evidencia a partir da literatura apresentada, é que as ações de consumo sustentável têm relação direta com a postura socialmente responsável das empresas (SOUZA, 2012) e da consciência dos consumidores.

Em relação à consciência ambiental ou ecológica, Bedante (2004) afirma que diversos estudos pesquisaram o tema, sendo que alguns autores sugerem que existe uma ideia generalizada de que um amplo conhecimento a respeito da ecologia leva a uma atitude sustentável em relação ao meio ambiente. $\mathrm{O}$ mesmo autor conclui ainda em seu estudo que a consciência ambiental influencia as atitudes de consumo sustentável das pessoas. Contudo, os resultados empíricos anteriores apresentam que é necessário haver algum conhecimento a respeito de determinado assunto para que o indivíduo venha a ter uma atitude positiva ou negativa em relação a ele, o que vem a fortalecer um estudo que traga novas evidências empíricas sobre o tema, principalmente utilizando uma amostra diferente da análise original. No próximo capítulo apresentam-se os procedimentos metodológicos que guiam a parte empírica deste trabalho. 


\section{PROCEDIMENTOS METODOLÓGICOS}

A pesquisa compõe-se uma abordagem quantitativa e descritiva, buscando descrever características de uma determinada população (MALHOTRA, 2001). A operacionalização do estudo ocorreu por meio de uma pesquisa survey com pessoas residentes/domiciliadas fora do Brasil. Como um esforço inicial, não limitou-se os respondentes por países, isto é, os respondentes pertencem a diversos países (exceto Brasil). Assim, buscou-se verificar, de forma ampla o comportamento dos estrangeiros sobre os temas propostos.

De modo específico, o universo da pesquisa foi composto por pessoas de nacionalidade estrangeira, isto é, não brasileiros (nem natos e nem naturalizados), residentes em qualquer país. Definiu-se a amostra como os questionários retornados e completamente preenchidos, onde obteve-se um total de 84 questionários. Após a identificação de missing values e outliers 78 questionários foram considerados válidos. Infere-se que a amostra não pode ser considerada como probabilística, haja vista que a probabilidade de inclusão de cada membro da população na amostra não é conhecida e nem equivalente (MALHOTRA, 2001).

Reproduziu-se as escalas de pesquisa propostas por Azevêdo et al. (2010) e Bedante (2004) em relação à consciência ambiental e de Souza (2012) sobre consumo sustentável. A tradução da escala foi feita por um americano nativo e revisada por um especialista na área. A nova versão em inglês foi traduzida de volta ao português, sendo que as duas versões foram comparadas e consideradas equivalentes.

As questões do roteiro de pesquisa foram compostas por uma escala Likert de cinco pontos (1-5), variando de 'discordo totalmente (1) a concordo totalmente (5)', bem como por uma escala do tipo Likert de cinco pontos (1-5), variando de 'não se parece nada comigo (1) a se parece muito comigo (5)'. A coleta de dados primários ocorreu entre os meses de agosto e outubro de 2013, por meio de levantamento online (Google docs.)

Os dados coletados na etapa quantitativa foram analisados com o auxílio do software PASW Statistics 18, por meio da adoção de análises estatísticas descritivas e univariadas, sendo média, desvio padrão, valores mínimo e máximo observados. 


\section{RESULTADOS}

Esta seção apresenta os resultados auferidos no levantamento, apresentando inicialmente a descrição do perfil dos respondentes. Após, apresentam-se os resultados da análise dos construtos de consciência ambiental e consumo sustentável.

Primeiramente procedeu-se a validação do banco de dados, por meio da identificação de missing values e outliers. Os missing values foram identificados por uma distribuição de frequência simples dos dados faltantes, sendo que todos os questionários foram eliminados (seis questionários). Os outliers foram identificados por meio do cálculo $Z$ Score, onde todos os dados demonstraram valores menores que 3 (HAIR Jr. et al., 2005). Dessa forma, na análise univariada de outliers não excluiu-se questionários.

Em seguida fez-se a análise de normalidade univariada, que foi verificada pelo cálculo de assimetria (skewness) e curtose (kurtosis), sendo que todas as variáveis observáveis do estudo apresentaram índices de normalidade adequados, isto é, valores absolutos de assimetria inferiores a 3 e valores absolutos de curtose inferiores a 8 (KLINE, 2011).

Após a validação do banco de dados, a amostra do estudo compreende a 78 questionários retornados considerados válidos. Obteve-se respondentes de 26 países, sendo que a distribuição geográfica dos respondentes corresponde à Alemanha $(11,5 \%)$, Austrália (2,6\%), Áustria (1,3\%), Bélgica (9\%), Catar (1,3\%), Chipre (2,6\%), Coréia (1,3\%), Croácia (14,1\%), Espanha (1,3\%), Estados Unidos da América $(14,1 \%)$, França (3,8\%), Japão (1,3\%), Líbano (1,3\%), Macedônia (3,8\%), México (3,8\%), Polônia $(1,3 \%)$, Portugal $(11,5 \%)$, Reino Unido $(5,1 \%)$, República Democrática do Congo $(1,3 \%)$, Romênia $(1,3 \%)$, Rússia $(1,3 \%)$, Sérvia $(1,3 \%)$, Suíça $(1,3 \%)$, Turquia $(1,3 \%)$, Uruguai (1,3\%) e Venezuela (1,3\%).

O levantamento da idade média dos respondentes ficou em 31 anos, sendo a idade mínima registrada 17 anos e a máxima 56 anos. No que tange gênero, a amostra é composta por $65,4 \%$ de mulheres e $34,6 \%$ de homens. Em relação ao estado civil, houve mais respondentes solteiros(as) representando 69,2\%, 29,5\% dos respondentes estão casados(as) ou em união estável e 1,3\% encontram-se separados(as) ou divorciados(as). E o que refere-se a escolaridade, houve maior número de respondentes com graduação $(33,3 \%)$ e pós-graduados $(30,8 \%)$, além de estudantes $(23,1 \%)$ e respondentes sem grau acadêmico $(12,8 \%)$.

Na perspectiva de identificar a consciência ambiental da amostra, partiu-se para a análise univariada dos construtos, onde avaliou-se o padrão médio de respostas da amostra para cada uma das variáveis observáveis (manifestas). Para tanto, considerou-se as estatísticas de média e valores mínimo e máximo observados.

No construto de consciência ambiental são dispostos cinco subconstrutos, sendo eles: comportamento em relação a produtos, comportamento em relação a 
embalagens e reciclagem, comportamento em relação a alimentos, relação a consumo de energia e consciência ambiental. Os resultados da análise podem ser visualizados na Tabela 1.

\section{COMPORTAMENTO EM RELAÇÃO A PRODUTOS}

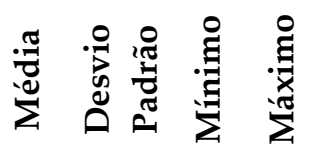

Quando possível, eu sempre escolho produtos que causam menor poluição.

Eu sempre faço um esforço para reduzir o uso de produtos feitos de recursos naturais escassos.

$3,67 \quad 0,935 \quad 1 \quad 5$

Quando eu compro produtos e alimentos as preocupações com o meio ambiente interferem na minha decisão de compra.

$3,53 \quad 0,893 \quad 1 \quad 5$

$3,42 \quad 1,013 \quad 1 \quad 5$

Eu não compro produtos e alimentos que podem causar a extinção de algumas espécies animais e vegetais.

$3,58 \quad 1,013 \quad 1 \quad 5$

Quando eu conheço os possíveis danos que um produto pode causar ao meio ambiente, eu não compro este produto.

$3,71 \quad 1,033 \quad 1 \quad 5$

Quando eu tenho que escolher entre dois produtos iguais, eu sempre escolho o que é menos prejudicial às outras pessoas e ao meio ambiente.

$3,69 \quad 1,120 \quad 1 \quad 5$

Eu não compro produtos para minha casa que prejudicam o meio ambiente. $\quad 3,19 \quad 1,070 \quad 1 \quad 5$

Eu não compro produtos fabricados ou vendidos por empresas que prejudicam ou desrespeitam o meio ambiente.

$3,31 \quad 1,048 \quad 1 \quad 5$

Eu já troquei ou deixei de usar produtos por razões ecológicas.

$3,41 \quad 1,098 \quad 1 \quad 5$

Eu já convenci amigos e parentes a não comprar produtos que prejudicam o meio ambiente.

$3,01 \quad 1,111 \quad 1 \quad 5$

\section{COMPORTAMENTO EM RELAÇÃO A EMBALAGENS E RECICLAGEM}

\begin{tabular}{lllll}
\hline Eu procuro comprar produtos feitos papel reciclado. & 3,65 & 0,965 & 1 & 5 \\
\hline Eu tento comprar apenas produtos que podem ser reciclados. & 3,33 & 1,028 & 1 & 5 \\
\hline $\begin{array}{l}\text { Eu procuro não comprar produtos que possuem grande quantidade de } \\
\text { embalagem. }\end{array}$ & 3,40 & 1,121 & 1 & 5 \\
\hline Sempre que possível, eu compro produtos feitos com material reciclado. & 3,60 & 1,097 & 1 & 5 \\
\hline Eu evito comprar produtos com embalagens que não são biodegradáveis. & 3,06 & 1,024 & 1 & 5 \\
\hline
\end{tabular}

\section{COMPORTAMENTO EM RELAÇÃO A ALIMENTOS}

\begin{tabular}{lllll}
\hline Eu compro produtos orgânicos porque são mais saudáveis. & 3,24 & 1,153 & 1 & 5 \\
\hline $\begin{array}{l}\text { Eu prefiro produtos e alimentos sem agrotóxicos porque eles respeitam o meio } \\
\text { ambiente. }\end{array}$ & $3,561,076$ & 1 & 5 \\
\hline $\begin{array}{l}\text { Eu estou disposto (a) a pagar um pouco mais por produtos e alimentos que } \\
\text { estão livres de elementos químicos e que prejudicam o meio ambiente. }\end{array}$ & $3,591,156$ & 1 & 5 \\
\hline
\end{tabular}

RELAÇÃO A CONSUMO DE ENERGIA 


\begin{tabular}{|c|c|c|c|c|}
\hline Eu sempre tento usar eletrodomésticos fora do horário de pico de consumo. & 2,95 & 1,018 & 1 & 5 \\
\hline Eu comprei lâmpadas mais caras, mas que economizam mais energia elétrica. & 3,62 & 1,119 & 1 & 5 \\
\hline Eu procuro comprar eletrodomésticos que consomem menos energia. & 3,82 & 1,054 & 1 & 5 \\
\hline \multicolumn{5}{|l|}{ CONSCIÊNCIA AMBIENTAL } \\
\hline $\begin{array}{l}\text { Plantas e animais existem basicamente para serem utilizados pelos seres } \\
\text { humanos (R). }\end{array}$ & 2,19 & 1,228 & 1 & 5 \\
\hline $\begin{array}{l}\text { Estamos nos aproximando do número limite de habitantes que a terra pode } \\
\text { suportar. }\end{array}$ & 3,36 & 1,248 & 1 & 5 \\
\hline $\begin{array}{l}\text { Para manter uma economia saudável teremos que desenvolvê-la de forma que o } \\
\text { crescimento industrial seja controlado. }\end{array}$ & 3,88 & 1,105 & 1 & 5 \\
\hline O planeta Terra é como uma espaçonave, com espaço e recursos limitados. & 4,01 & 1,190 & 1 & 5 \\
\hline $\begin{array}{l}\text { Os seres humanos não precisam se adaptar ao ambiente natural porque podem } \\
\text { adaptar o meio ambiente às suas necessidades (R). }\end{array}$ & 2,37 & 1,340 & 1 & 5 \\
\hline $\begin{array}{l}\text { Existem limites de crescimento para além dos quais a nossa sociedade } \\
\text { industrializada não pode se expandir. }\end{array}$ & 3,59 & 1,145 & 1 & 5 \\
\hline O equilíbrio da natureza é muito delicado e facilmente perturbado. & 4,04 & 1,098 & 1 & 5 \\
\hline $\begin{array}{l}\text { Quando os seres humanos interferem na natureza, isso frequentemente produz } \\
\text { consequências desastrosas. }\end{array}$ & 3,94 & 1,036 & 1 & 5 \\
\hline $\begin{array}{l}\text { Os seres humanos têm o direito de modificar o meio ambiente para ajustá-lo às } \\
\text { suas necessidades (R). }\end{array}$ & 2,49 & 1,170 & 1 & 5 \\
\hline A humanidade foi criada para dominar a natureza (R). & 2,41 & 1,381 & 1 & 5 \\
\hline
\end{tabular}

Tabela 1 - Análise univariada do construto de consciência ambiental

Fonte: elaborado pelas autoras (2014)

Nota: (R) Variável reversa (ou seja, menores escores mostram mais consciência).

No subconstruto de comportamento em relação a produtos observa-se que os respondentes mostram-se indiferentes em relação à sua preocupação na compra e consumo de produtos ambientalmente corretos, uma vez que as médias variam entre 3,01 e 3,71. Em tempo, os resultados evidenciam que existe pouco hábito de convencer amigos e parentes a não comprar produtos que prejudicam o meio ambiente (resultado que corrobora com os achados de Bedante (2004) junto a amostra de brasileiros), mas quando se refere a si próprio na variável 'quando eu conheço os possíveis danos que um produto pode causar ao meio ambiente, eu não compro este produto', 67,9\% (considerando os respondentes que concordam ou concordam totalmente) dos respondentes demonstram estar conscientes. Em tempo, os respondentes procuram escolher produtos menos prejudiciais ás outras pessoas e ao meio ambiente $(3,69)$.

O subconstruto de comportamento em relação a embalagens e reciclagem mostra a mesma tendência, apresentando médias que variam entre 3,06 a 3,65. Os resultados evidenciam que os respondentes preferem comprar produtos em que haja pouca quantidade de embalagem, seja do tipo reciclável ou feitas com material 
reciclável, embora que mostram-se indiferentes em evitar comprar produtos com embalagens que não são biodegradáveis.

O comportamento em relação a alimentos as médias apresentam-se entre 3,24 e 3,59, sendo que a amostra indica comprar produtos orgânicos pensando que são mais saudáveis (o que pode não ser sustentável, sendo que linhas de estudos apontam que produtos orgânicos utilizam mais recursos naturais), ao mesmo tempo que preferem produtos e alimentos livres de agrotóxicos por acreditar que desta forma estão respeitando o meio ambiente. Da mesma forma, a amostra indica uma pré-disposição a pagar um pouco mais por produtos e alimentos que estão livres de elementos químicos e que prejudicam o meio ambiente.

O subconstruto de consumo de energia mostra que a os respondentes não têm hábitos de usar eletrodomésticos fora do horário de pico de consumo $(2,95)$, mas, se preocupam em economizar energia comprando lâmpadas mais caras (média 3,62) e eletrodomésticos e consomem menos (média 3,82).

Especificamente sobre o subconstruto da consciência ambiental, as médias apresentam-se mais positivas em relação aos demais subconstrutos apresentados, considerando as diversas variáveis reversas. Verifica-se que os respondentes reconhecem que existe grande número de habitantes na terra que pode comprometer a sustentabilidade, que o crescimento industrial precisa ser controlado para manter a economia saudável, que a natureza pode ser facilmente atingir um desequilíbrio e o que o ser humano quando interfere pode provocar consequências desastrosas e reconhecem que isto está acontecendo. Ressalta-se a variável "os seres humanos devem viver em harmonia com a natureza para que possam sobreviver melhor" onde $60,3 \%$ dos respondentes concordaram totalmente com a afirmação.

Em uma análise geral sobre o construto de consciência ambiental, compreende-se que a amostra mostra-se indiferente, sendo que as médias e a concentração de respondentes por níveis de intensidade apareceram mais no nível 3 da escala, ou seja, neutro (nem concorda e nem discorda). Esses resultados mostram a disposição das pessoas em respeitar o meio ambiente, desde que os meios utilizados para isso não afetem seu próprio conforto e bem-estar.

Esses resultados mostram que existe uma diferença considerável entre os resultados auferidos por Bedante (2004), onde sua amostra demonstrou consciência ambiental, em grosso modo, elevada (isto é, médias superiores a 4 na análise dos construtos secundários). A amostra desse autor era composta por 606 respondentes brasileiros, basicamente estudantes, sendo a média de idade 26 anos (mais jovens que a amostra desse estudo), mais respondentes do gênero masculino (56,3\%) (diferente da amostra desse estudo que obteve mais respondentes do gênero feminino), solteiros (78,5\%) (similar a esse estudo), e grande maioria da amostra (mais de 95\%) possuíam ou estavam cursando grau acadêmico (similar a amostra desse estudo). Se observadas as características dos respondentes verifica-se que são similares, o que 
aumentaria a influência da cultura nas respostas, e comparadas as diferenças de médias no que tange ao construto de consumo sustentável, evidencia-se que a amostra brasileira estaria mais consciente ambientalmente do que a amostra internacional obtida nesse estudo.

Antes de avançar para o próximo construto e considerar os resultados obtidos, observa-se que as variáveis observáveis utilizam-se de uma escala intervalar do tipo Likert de cinco pontos (1-5), sendo: 1 - Não se parece nada comigo; 2 - Não se parece comigo; 3 - Neutro; 4 - Se parece comigo; 5 - Se parece muito comigo. Os resultados desse construto podem ser observados na Tabela 2.

\section{CONSUMO SUSTENTÁVEL}

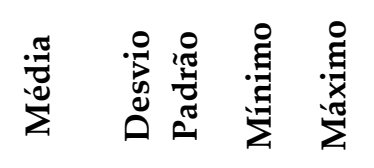

\begin{tabular}{|c|c|c|c|c|}
\hline $\begin{array}{l}\text { Você separa objetos de metal (latas de alumínio, óleo, extrato de tomate, etc.) } \\
\text { para reciclagem. }\end{array}$ & 3,58 & 1,344 & 1 & 5 \\
\hline $\begin{array}{l}\text { Nas eleições para cargos públicos, você prefere votar em candidatos que têm } \\
\text { posições firmes em defesa do meio ambiente. }\end{array}$ & 3,09 & 1,130 & 1 & 5 \\
\hline Você busca maneiras de reutilizar os objetos. & 3,67 & 0,963 & 1 & 5 \\
\hline Você tenta concertar as coisas em vez de jogá-las fora. & 3,72 & 0,966 & 1 & 5 \\
\hline $\begin{array}{l}\text { Você separa vidro (garrafas de cerveja, refrigerante, frascos de perfumes, } \\
\text { etc.) para reciclagem. }\end{array}$ & 3,69 & 1,209 & 1 & 5 \\
\hline $\begin{array}{l}\text { Você para de comprar de uma empresa que mostra desrespeito pelo meio } \\
\text { ambiente. }\end{array}$ & 3,59 & 0,918 & 1 & 5 \\
\hline Você compra produtos usados. & 2,90 & 1,169 & 1 & 5 \\
\hline $\begin{array}{l}\text { Você muda de marca para comprar de empresas que demonstram maior } \\
\text { cuidado com o meio ambiente. }\end{array}$ & 3,10 & 1,064 & 1 & 5 \\
\hline $\begin{array}{l}\text { Você deixa aparelhos, como televisão e computador, ligados mesmo quando } \\
\text { não os está utilizando. (R) }\end{array}$ & 2,95 & 1,216 & 1 & 5 \\
\hline Você separa papéis (jornais, revistas, livros, cadernos, etc.) para reciclagem. & 3,58 & 1,334 & 1 & 5 \\
\hline $\begin{array}{l}\text { Você fecha as torneiras da pia do chuveiro quando está ensaboando os } \\
\text { objetos, o corpo ou as mãos. }\end{array}$ & 3,37 & 1,186 & 1 & 5 \\
\hline Você deixa luzes acesas sem necessidade (R). & 2,27 & 1,136 & 1 & 5 \\
\hline $\begin{array}{l}\text { Você separa embalagens de plástico (sacolas, garrafas PET, copos } \\
\text { descartáveis, etc.) para reciclagem. }\end{array}$ & 3,73 & 1,255 & 1 & 5 \\
\hline
\end{tabular}

Tabela 2 - Análise univariada do construto de consumo sustentável

Fonte: elaborado pelas autoras (2014)

Nota: (R) Variável reversa (ou seja, menores escores mostram um consumo mais sustentável).

No que se refere ao consumo sustentável, os resultados mostram-se intermediários, sendo que os respondentes costumam separar seu lixo para reciclagem (médias: metal 3,58; vidro 3,69; papéis 3,58; embalagens plásticas 3,73), 
buscam reutilizar objetos $(3,67)$ ou tentam concertar as coisas em vez de jogá-las fora $(3,72)$. Contudo, a amostra não costuma comprar produtos usados $(2,90)$.

Infere-se ainda, na análise do construto de consumo sustentável que a amostra mostra-se indiferente na escolha de políticos preocupados/que defendem o meio ambiente $(3,09)$, pressupondo utilizarem-se de outras formas de análise na escolha dos candidatos. Ainda, quando refere-se à escolha das empresas, os respondentes mostram-se positivos em parar de comprar de empresas que mostram desrespeito pelo meio ambiente $(3,59)$, em tempo que possuem menos tendência a mudar de marca para comprar de empresas que demonstram maior cuidado com o meio ambiente $(3,10)$.

No que se refere a deixar aparelhos, como televisão e computador, ligados mesmo quando não os está utilizando (variável com análise reversa), 43,6\% dos respondentes afirma ter esse tipo de hábito e outros 19,2\% mostram-se indiferentes. Em tempo, a amostra não costuma deixar as luzes acesas sem necessidade, sendo que $62,9 \%$ afirmam não possuir esse comportamento e outros 19,2\% mostram-se neutros.

Evidencia-se dessa forma, que há um tímido consumo sustentável, corroborando com os resultados auferidos junto a amostra brasileira (BEDANTE, 2004), sendo que os brasileiros escolhem produtos que causam menos poluição sempre que possível. Da mesma forma também como a amostra internacional, a amostra brasileira mostrou que itens relacionados a verbos como prejudicar, desrespeitar e danificar, as respostas mostram uma atitude mais positiva para o consumo de produtos que minimizem esses tipos de implicações sobre a natureza.

Por fim, considerando os resultados de Bedante (2004) que conclui que a consciência ambiental influencia as atitudes de consumo sustentável e comparando aos resultados auferidos junto a amostra internacional, infere-se que ainda existe um longo caminho a ser percorrido em busca da consciência ambiental e consequentemente das atitudes de consumo sustentável, uma vez que os resultados possuem tendências neutras nas variáveis observáveis e ainda, em todas as questões, houve respondentes em todos os níveis de intensidade da escala. A partir disso, tecem-se no próximo capítulo as considerações finais sobre o estudo, as recomendações gerenciais e limitações acadêmicas.

\section{CONSIDERAÇÕES FINAIS}

Com objetivo de identificar a consciência ambiental e as atitudes de consumo sustentável de indivíduos no âmbito internacional, procedeu-se um levantamento junto a 78 respondentes (válidos), de 26 nacionalidades, em busca de contribuições teóricas e práticas para auxiliar as organizações que buscam se inserir no mercado internacional, de modo a fornecer informações na sua escolha da estratégia de 
marketing utilizada quanto ao tipo de produto, mais especificamente no que tange produtos e empresas/marcas sustentáveis.

O que pode-se evidenciar, em grosso modo, é que tanto a consciência ambiental quanto as atitudes de consumo sustentável da amostra possuem tendência intermediária, sendo que grande parte dos respondentes parece não utilizar-se do viés ambiental na escolha dos produtos que irá comprar e consumir. Infere-se ainda, que os respondentes mostram respeitar o meio ambiente, desde que os meios utilizados na implementação desse 'seu respeito' não afetem seu próprio conforto e bem-estar.

Gerencialmente, esses resultados mostram que os produtos disponibilizados pelas empresas no mercado internacional devem procurar diferenciar-se, atendendo outros tipos (não tão preocupados com sua imagem ambientalmente correta) de necessidades e desejos dos consumidores, principalmente produtos e serviços que ofereçam conforto e bem-estar. Evidente que isso não significa que a empresa pode utilizar meios que desrespeitem o meio ambiente, apenas esse fator mostra-se pouco determinante na escolha dos produtos a serem consumidos.

Academicamente, esse estudo trouxe uma nova contribuição teórica, especialmente aos achados de Bedante (2004), dez após anos de seu estudo original, bem como o estudo de uma nova amostra, que mesmo não muito representativa, traz importantes insights de análise.

Nada obstante, mesmo que esse estudo, como um esforço inicial de análise internacional, tenha alcançado seu objetivo, deve-se destacar suas limitações. Primeiramente, a amostra não pode ser considerada estatística e tampouco representativa do comportamento de consumo geral em âmbito internacional. Destarte, não deve-se tomar esses resultados como únicos e não refutáveis, sendo sugerido que novas análises sejam efetuadas junto a essa mesma população. Evidencia-se que houve dificuldade em acessar e conseguir respondentes, que mostravam certa desconfiança ao teor da pesquisa e a origem das pesquisadoras.

Finalmente, cabe inferir que as metodologias clássicas de investigação (a exemplo desse estudo que utilizou um levantamento do tipo survey) apresentam como limitante natural sua dificuldade em compreender que, em um mesmo indivíduo, podem existir estilos de consumo distintos, não conscientes, além de que o entrevistado pode, de maneira intencional ou não, compreender mal, interpretar mal ou omitir informações.

\section{REFERÊNCIAS}

ARANCIBIA, F. E. R. Consumo sustentável: padrões de consumo da nova classe média brasileira. Dissertação (Mestrado em Desenvolvimento Sustentável) - Centro de Desenvolvimento Sustentável - Universidade de Brasília, Brasília, 2012. 
AZEVÊDO, A. C.; CUNHA, F. R.; QUINELATO, R.; MADUREIRA, D. M. Consciência ambiental e comportamento do consumidor. In: XIII SEMEAD Sustentabilidade Ambiental nas Organizações, São Paulo, Anais... setembro, 2010.

BEDANTE, G. N. A influência da consciência ambiental e das atitudes em relação ao consumo sustentável na intenção de compra de produtos ecologicamente embalados. Dissertação (Mestrado em Administração) - Programa de Pós- Graduação em Administração - Universidade Federal do Rio Grande do Sul - UFRGS. Porto Alegre: 2004.

BERGER, I. E.; CUNNINGHAM, P. H.; DRUMWRIGHT, M. E. Identity, Identification, and Relationship through Social Alliances. Journal of the Academy of Marketing Science, v.34, p. 128-137, 2006.

CARSON, R. Silent Spring. Disponível em <http://www.science.smith.edu/ jcardell/Courses/EGR100/protect/reading/SilentSpri ng.pdf $>$. Acesso em 14/04/2013.

COSTA, B. G.; LANDEIRA, R.; SILVA, B. R. Made in Bahia: Estratégias de marketing internacional no setor de vestuário. In: XXXI Encontro da EnANPAD, Rio de Janeiro/RJ, Anais... setembro, 2007.

COSTA, D. V.; TEODÓSIO, A. S. S. Desenvolvimento Sustentável, Consumo e Cidadania: Um Estudo sobre a (des)articulação da Comunicação de Organizações da Sociedade Civil, do Estado e das Empresas. Revista de Administração Mackenzie, v.12, n.3, p.114-145, 2011.

CUNHA, R. D.; ROCHA, T. V. A influência das atividades de marketing na performance exportadora de países emergentes: um modelo conceitual adaptado a MPE's brasileiras. In: XXXV Encontro da EnANPAD, Rio de Janeiro/RJ, Anais... setembro, 2011.

DIAS, R. Gestão ambiental: responsabilidade social e sustentabilidade. - 1ํee.

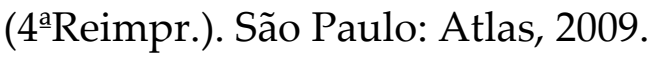

ELKINGTON, J. Partnerships from Cannibals with forks: The Triple Bottom Line of $21^{\text {st }}$ Century Business. Environmental Quality Management, Autumn, p. 37-51, 1998. 
GORNI, P. M.; GOMES, G.; DREHER, M. T. Consciência ambiental e gênero: os universitários e o consumo sustentável. In: Simpósio de Administração da Produção, Logística e Operações Internacionais, São Paulo/SP, Anais... Agosto, 2011

HAIR Jr., J. F.; ANDERSON, R.E.; TATHAM, A.R.L.; BLACK, W.C. Análise multivariada de dados. 5ª ed. Porto Alegre: Bookman, 2005

HARTMANN, P.; IBÁÑEZ, V.A. Green value added. Marketing Intelligence \& Planning, v. 24, n. 7, p. 673-680, 2006.

HASWANI, M. A comunicação do Estado democrático de direito na mobilização para a sustentabilidade. In: III Congresso Brasileiro Científico de Comunicação Organizacional e Relações Públicas (Abrapcorp), São Paulo/SP, Anais... abril, 2008.

KINNEAR, T. C.; TAYLOR, J.R. The Effect of Ecological Concern on Brand Perceptions: an application of insdcal. Bureau of Business Research - Working Paper n. 62 - University of Michigan, 1972.

KLINE, R. B. Principles and practice of structural equation modeling. $3^{\underline{a}}$ ed. New York, Guilford, 2011.

LAROCHE, M.; BERGERON, J.; BARBARO-FORLEO, G. Targeting consumers who are willing to pay more for environmentally friendly products. Journal of Consumer Marketing, v. 18, n.6, p. 503-520, 2001.

MALHOTRA, N. K. Pesquisa de marketing: uma orientação aplicada. 3aed. Porto Alegre/RS: Bookman, 2001.

MEADOWS, D. H. et al. The Limits to Growth, 1972. Disponível em <http://ebookbrowse.com/club-of-rome-limits-to-growth-1972-pdf-d476830576>.

Acesso em 22/03/2013.

MINISTÉRIO DO MEIO AMBIENTE. O que é Consumo Sustentável. Disponível em $<$ http://www.mma.gov.br/estruturas/234/ arquivos/popupcsust 234 3.jpg >. Acesso em 15/05/2013.

NASCIMENTO, E. P. Trajetória da sustentabilidade: do ambiental ao social, do social ao econômico. Estudos Avançados, v.26, n.74, vol.26, n.74, pp. 51-64, 2012. 
OLIVEIRA, L.R. et al. Sustentabilidade: da evolução dos conceitos à implementação como estratégia nas organizações. Produção, v.22, n.1, São Paulo, jan-fev. 2012.

Our Common Future (1987). Disponível em http://www.un-documents.net/ocf02.htm. Acesso em 22/03/2013.

PORTILHO, F. Consumo sustentável: limites e possibilidades de ambientalização e politização das práticas de consumo. Cadernos EBAPE, v.3, n.3, p.1-12, 2005.

ROMEIRO, A. R. Desenvolvimento sustentável: uma perspectiva econômicoecológica. Estudos Avançados, v.26, n.74, p.65-92, 2012.

SAAD, A. D.; MELLO, R.C.; CHAUVEL, M.A. Estratégia Global e Adaptação Local: Um Estudo de Caso no Setor Financeiro Brasileiro. In: XXX Encontro da Anpad, Salvador/BA, Anais... setembro, 2006.

SANCHES, C. S. Gestão Ambiental Proativa. Revista de Administração de Empresas, v.40, n.1, p.76-87, 2000.

SANTOS, C. A. F.; SILVA, T.N. Descompasso entre a Consciência Ambiental e a Atitude no Ato de Descartar Lixo Eletrônico: A Perspectiva do Usuário Residencial e de uma Empresa Coletora. In: XXXV Encontro da ANPAD, Rio de Janeiro/RJ, Anais... setembro, 2011.

SOLBERG, C. A. The Perennial Issue of Adaptation or Standardization of International Marketing Communication: Organizational Contingencies and Performance. Journal of International Marketing, v.10, n.3, p.1-21, 2002.

SOUZA, J. V. R. Verificação da relação entre os valores pessoais e a predisposição ao consumo sustentável. Dissertação (Mestrado em Administração) - Programa de PósGraduação em Administração - Universidade Federal do Rio Grande do Sul UFRGS. Porto Alegre: 2012.

TÓDERO, M.; MACKE, J. Consumo Consciente e Capital Social: Medindo a Relação entre os Conceitos. In: X Encontro Nacional de Gestão Empresarial e Meio Ambiente (ENGEMA), Porto Alegre/RS, Anais... novembro, 2008. 